\title{
The circular economy in the agro-zootechnical industry
}

\author{
Ancuta Ioana Hălmaciu ${ }^{1}$, Ioana Ionel ${ }^{1}$ and Mihail Reinhold Wächter ${ }^{1}$ \\ ${ }^{1}$ Politehnica University of Timisoara, Faculty for Mechnical Engineering, Bv. M. Viteazu, Nr. \\ 1, 300222, Timisoara, Romania \\ E-mail: ioana.halmaciu@student.upt.ro
}

\begin{abstract}
The excessive acquisition and the careless usage of the food and non-food products in the recent years have led to the result of a huge amount of waste, which in time has become a real problem at a global level.

In order to solve this issue rapidly and efficiently, the researchers have been forced to find prompt, vast, efficient and inexpensive solutions.

The aim of this paper is to emphasise the importance and the benefits of the circular economy as a possibility to be applied in the agro-zootechnical sector. Opposing the linear economy and the recycling economy, the circular economy has the main objective of reducing the waste to minimum, expecting even a 'zero waste'.
\end{abstract}

Keywords: circular economy, biogas, agro-zootechnology

\section{Introduction}

There is no secret for anyone the fact that one lives in an era when the increasing development of the industry and the demographic increase of the population are two important factors which have indirectly produced negative effects upon the climate as a result of the pollution caused by the inappropriate managing of the waste. The planet has suffered dramatical changes, and in order to stop these in the future, the specialists in the waste managing have to find innovator solutions to change them into raw materials that are necessary for certain economy branches. Recently, at a global level, the population has been educated due to the principle` buy-use-waste', a totally wrong principle as it has caused a huge amount of waste whose impact on the Planet will be devastating unless quick measures of reeducating the people are taken with a view of reusing it. The researchers sustain that it is necessary to implement a new strategy which has to be based on an innovative concept whose essence is the principle of 'reuse-repair-recycle', this concept is labeled in the circular economy. This concept appeared in the 1970s, being spread in the field of economy and the management of the business processes. The main principle of this is based on the continual reuse of waste in different forms, having as aim its significant reduction and also the reduction of the negative impact on the environment.

The waste that is resulted from the agro-zootechnical field could represent a real of income, provided they are properly managed. If not, they can have negative effects on the ecosystems, becoming a danger for man and nature, by producing a vast amount of methane emissions and by attracting a significant amount of insects and rodents [1]. The most efficient solution to value this waste is to produce biogas. The new branch that is continually developing [2], this method of obtaining electrical and thermal energy has started to attract more and more followers among the agricultural waste [3]. 
To put this in a simplified way, one can state that the circular economy is an economy which produces zero waste [4].

Analysing the real condition of managing the waste we can state that currently the linear economy mostly prevails the market, respectively the recycling economy. The circular economy is little known and used, although it has an efficient method of reducing the waste and the production costs for certain products.

The new approach that this concept brings about consists in the fact that since the moment of manufacturing [5], the products are designed so as to be easily reused to obtain other products. Practically, the circular economy relies on 'circuits closing` [6], the extension of the life expectancy of the products, using as main activities: the fixing and the remaking of the products, as well as the avoiding of the resource wasting while the economical increasing is sustained.

The graphic chart representative for the three types of economy is illustrated in figure 1 .
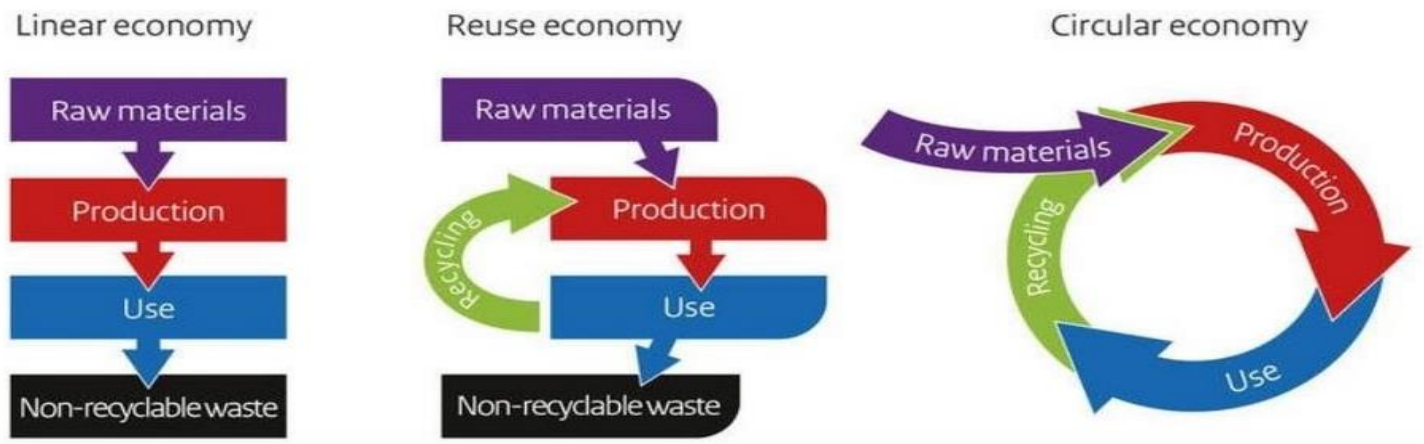

Figure 1. From linear economy to circular economy [7].

\subsection{The advantages of a circular economy}

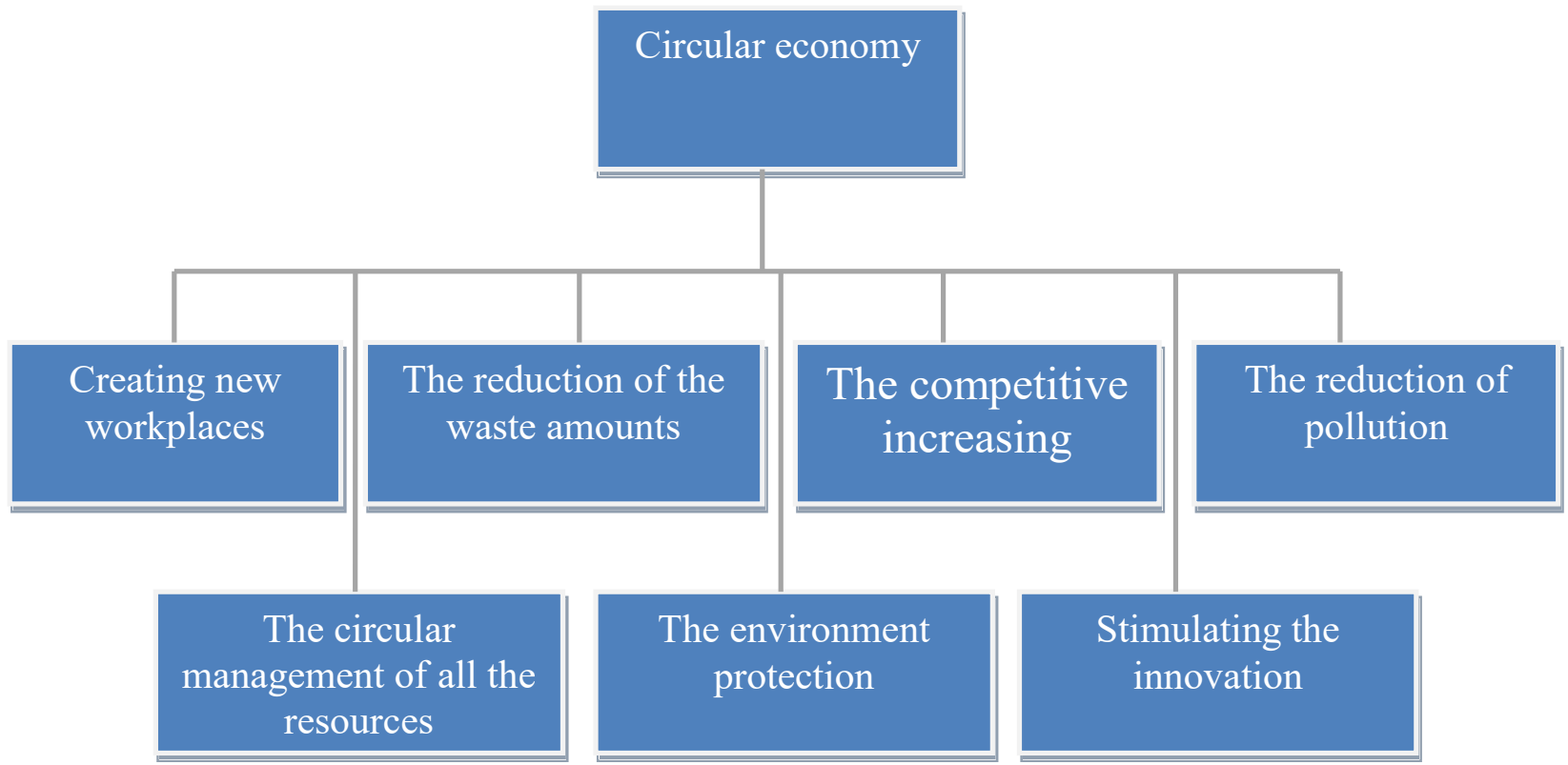

Figure 2. The benefits of a circular economy. 
Despite being at the beginning, the circular economy presents a significant number of both economical and ecological advantages. Thus one can state that the circular economy is 'a catalyser for mutual benefit' [8]. Figure 2 indicates the main benefits of the circular economy.

\subsection{The principles of the circular economy in the agro-feeding department}

In the agro-feeding department the circular economy is based on three important pillars:

Pillar 1: relies on vegetal biomass which constitutes the vital element in forming carbon cycle. The forming process consists of the diversity of the crops and of the use of the bio fertilisers.

At the same time this process, which relies on the circular economy uses a variety of waste as raw material which can be: animal, vegetable, organic or green.

Pillar 2: relies on the use of waste that are resulted from reuse of secondary products in the agrofeeding system. By processing this waste, one could obtain and value both renewable energy and organic fertilisers.

Pillar 3: has as main objective the use at maximum the resources obtained from zootechnical farms. As the animal waste changed into compost consists of a high quality fertiliser which thrown on the agricultural grounds will constitute an important nutritious source for the plants. On their turn, the plants will grow vigorously and rich in essential nutrients for the breeding and growing of the animals [9].

1.2. The agro-zootechnical industry, one of the most important and greatest suppliers of organic waste Being an important branch in economy, the agro-zootechnical industry significantly contributes to the economical increase of every country that put a big emphasis on this industry. Thus the countries where the agro-zootechology is developed and sustained, become the greatest suppliers and exporters of food products. While in other fields the resources are exhaustible, in the agricultural field these are in continual changing, as well as renewing [10].

The intensive development of the agro-industrial sector has led to the increasing of the pollution degree worldwide [11].

Because the waste obtained from the agro-zootechnical industry are mostly solid waste and can be found in significant amounts, it needs to be managed and stored carefully otherwise it can become an important source of pollution for air, water and soil. As a consequence it becomes a potential danger for the human and animal health [12].

The main industries which produce biodegradable waste in the agro-feeding system are: in the industry of products and drinks, the animal breeding and the fito-technical waste industry [13].

\subsection{The biogas as part of the circular economy}

The biogas is a biological product that is obtained by anaerobic fermentation using organic materials produced from municipal waste, drainage, biomass, farming waste, waste from the agricultural crops and plants [14], the mud from the water purification stations and the agro-industrial waste. The process of anaerobic fermentation is usually applied for the control of the air and water pollution [15]. The first four important stages that provide the production of gas are: hydrolize, acidogenesis, acetogenesis and methanogenesis [16].

The biogas is mostly made up of methane in an amount of $60 \%$, carbon dioxid $40 \%$ [17], but in fewer amount there can be found the anitrogen, hydrogen sulfide and the oxygen.

The main use of the biogas consists in the producing of the electrical and thermical energy that is used at the given place or charged in the national network [18].

A continual increasing use of the biogas is the bio-methane. This is obtained with the help of the absorbtion technique at an oscillate pressure, the cleaning under pressure. The physical absorbtion with organic matter, and the cryogenic separation of the bio-methane could be used as a fuel for the gas vehicles. Also it is found that the bio-methane is very useful in the in the chemical industry, but also for the domestic and trading uses, as it proofs to have the same benefits as the natural gases [19, 18], in addition to the real advantage that it represents a neutral $\mathrm{C}$ emission fuel. 
The digestate obtained as a result of the process of anaerobic digest is considered a bio fertilizer rich in ammonium and phosphate nutrient. The obtaining of the compost is quite easy and is very advantageous on the three levels: local, regional and extra-regional [20].

Unlike the stable mud, the compost does not contain germ seeds of weeds and pathogen microorganisms because they die even since the first stage of production when the temperature in the compost platform rises to $70^{\circ} \mathrm{C}[21]$.

A brief overview of the opportunities that the circular economy brings up within the supplying chain is presented in figure 3 .

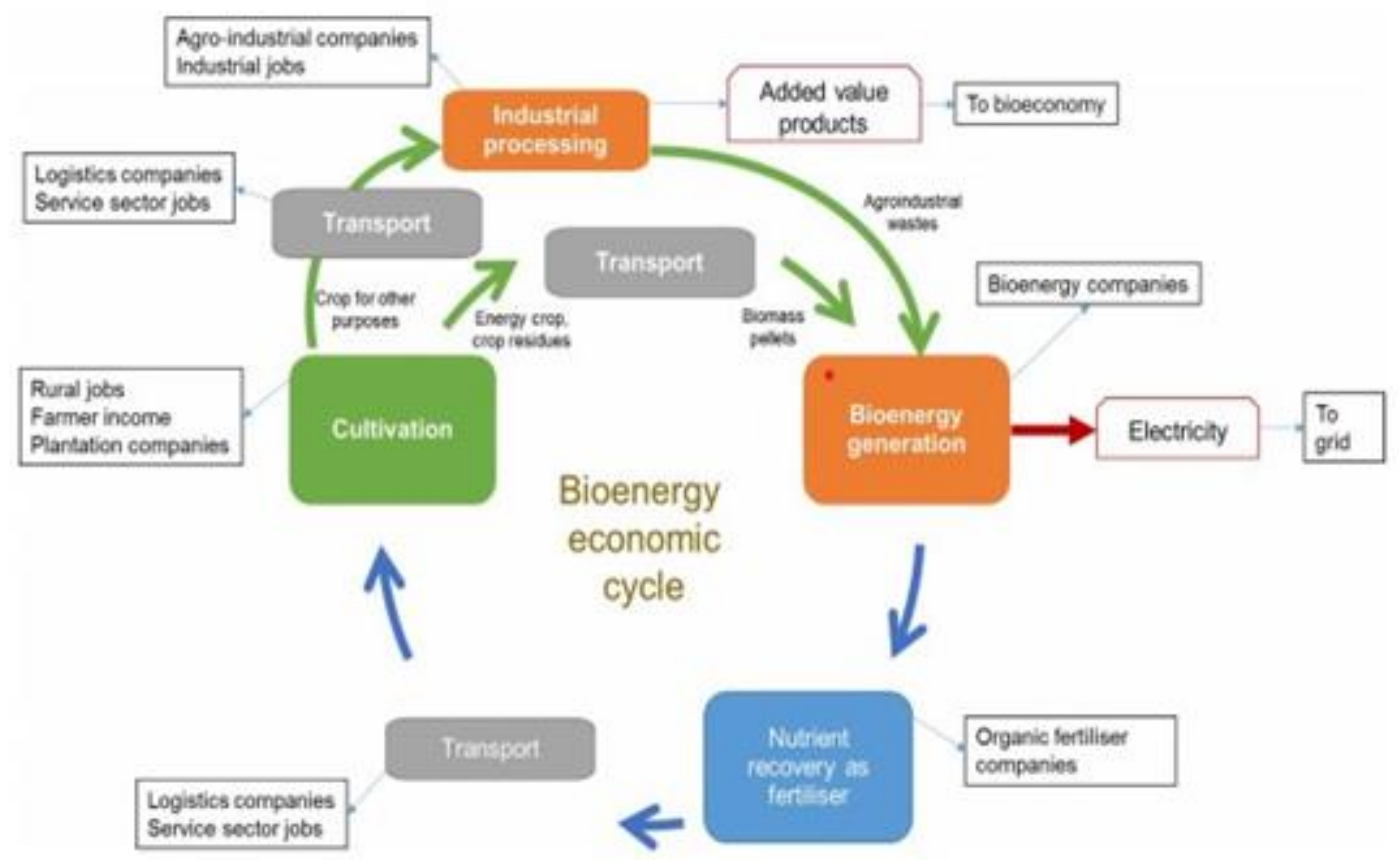

Figure 3. A conceptual diagram of bioenergy economic cycle [22].

\subsection{Conclusions}

The paper focuses on the novel idea of the circular economy, presenting in short the benefits and possibilities to be applied in the agricultural sector.

The new concept of the circular economy can be considered an important step that the researchers have taken in the 'war' concerning the reduction of the waste and the pollution of the environment. The main idea that lies at the basis of this concept is the reuse of the waste in a variety of ways. The circular economy, unlike the linear economy and the recycling economy, has numerous advantages such as: creating new workplaces, the increasing of the competition, the reduction of pollution, the reduction of the waste amount. Another major advantage of this concept is that it can be implemented in all the active systems and this thing can be regarded as an opportunity for business people. The development of the agro-zootechnical sector has led to the creation of a big amount of waste and so there should be imposed the implementation of the circular economy through the biogas production.

The waste resulted from this sector, when it is improperly stored, turns into a real problem both for the generator and for the environment. The construction of the biogas installation can transform this waste into real inexhaustible 'deposits'. The reduction of the waste costs, the production of the electrical and thermal energy, the obtaining of the bio-methane and the production of the compost are but a few advantages that a biogas installation can bring about. 
The authors consider that all the benefits mentioned above should determine those who act in the agro-zootechnical sector and mainly on legislative level to take into account the designing of a biogas installation.

\section{Acknowlwdgement}

The paper is written in the frame of the doctoral program of the first author. Thanks are addressed to the Doctoral School of the Politehnica University of Timisoara, as well to the guidance staff .

\section{References}

[1] Schoenmakere De M, Hoogeveen, Gillabel J and Manshoven S 2018 The circular economy and the bioeconomy, Parteners in sustainability, ISSN 1977-8449, EEA Report, No.8

[2] Postawa K, Szczygieł J, Jędrusiak- Wrzesińska E, Klimek K and Kułażyński M 2021 The pump-mixed anaerobic digestion of pig slurry: new technology and mathematical modeling, 15 March, pp 111-119

[3] Varbanov S P and Walmsley G T 2019 Circular economy and engineering concepts for technology and policy development, Springer-Verlag GmbH Germany, part of Springer Nature 2019, 8 March, 21 pp 479-480

[4] ***https://www.ecotic.ro/welcome-change/economie-circulara/episodul1/, accessed: 07.02.2021

[5] ***https://www.solutiidemediu.ro/primii-pasi-catre-economia-circulara-in-romania/, accessed: 08.02.2021

[6] ***https://www.startupcafe.ro/idei-antreprenori/conferinta-internationala-economia-circulararegiunea-balcanilor-de-vest-2020, accessed: 09.02.2021

[7] $* * *$ https://www.revistamobila.ro/industria-mobilei-si-economia-circulara-un-scenariuprognoza-pentru-2030/, accessed: 17.02.2021

[8] ***https://theworldnews.net/ro-news/studiu-economia-circulara-in-ue-este-corelata-cu-300380-miliarde-euro-din-pib-in-2018-si-10-12-miliarde-euro-in-romania, 07.02 .2021

[9] ***https://bioresurse.ro/blogs/media/economia-circulara-in-cadrul-sistemului-agroalimentar, accessed: 10.02 .2021

[10] ***http://www.managusamv.ro/english/images/pdf/ECONOMIERURALA.pdf, accessed: 05.02 .2021

[11] Muscio A and Sisto R 2020 Are Agri-Food Systems Really Switching to a Circular Economy Model? Implications for European Research and Innovation Policy, Journal Sustainability, 10 July, 12

[12] Escobar-Orejuela M L, Landázuri C A and Goodell B 2020 Second Generation Biorefining in Ecuador: Circular Bioeconomy, Zero Waste Technology, Environment and Sustainable Development: The Nexus, Journal of Bioresources and Bioproducts, 1 November

[13] Șalaru G, Bahnaru A, Jolondcovschi A, Osipov R and Golic A 2013 Biodegradable waste management (Material and energy recovery), MINISTRY OF THE ENVIRONMENT, ASSOCIATION FOR WASTE RECOVERY, OFFICE ON COMBATING CLIMATE CHANGE IN AGRICULTURE, Chișinău

[14] Dahiya S, Katakojwala R, Ramakrishna S and Mohan Venkata S 2020 Biobased Products and Life Cycle Assessment in the Context of Circular Economy and Sustainability, Springer Nature Singapore Pte Ltd. 2020, 7 September, 2

[15] Fakkaew K and Polprasert C 2021 Air stripping pre-treatment process to enhance biogas production in anaerobic digestion of chicken manure wastewater, June,

[16] Haque E Md, Ryndin R, Mang P-H, Kabir H, Rahman M M, Khasruzzaman M K A,Uddin A M and Islam A Md 2021 Evalution of biogas production from manure of hybrid and local 
breed cows fed with different types of feeding practices, ISSN: 2315-9766, Net Journal of Agricultural Science, Vol. 9 (1), January, pp. 1-8

[17] Oreggioni D G, Luberti M, Reilly M, Kirby E M, Toop T, Theodoru M and Tassou A S 2017 Tehnico-economic analysis of bio-methane production from agriculture and food industry waste, pp 81-88

[18] Blades L, Morgan K, Douglas R, Glover S, Rosa De M, Cromice T and Smyth B 2017 Circular Biogas-Based in a Rural Agricultural Setting, pp 89-96

[19] Colmorgen F, Khawaja C, Rutz D M Anual on bioeconomies and local bioeconomies,, ISBN 978-3-936338-64-5, WIP Renewable Energies, Munchen, Germania, 2020

[20] ***https://www.compostnetwork.info/policy/circular-economy/bio-waste-management/, accessed: 11.02 .2021

[21] Toncea I, Enuță S, Niţu I G, Alexandrescu D and Toncea A V Organic farming manual

[22] Sadhukhan J, Hernandez-Martinez E, Murphy J R et al. 2018 Role of bioenergy, biorefinery and bioeconomy in sustainable development: Strategic pathways for Malaysia, pp 1966-1987 